\title{
Trends of Colorectal Cancer Incidence in Kazakhstan
}

\author{
Dana Mauyenova ${ }^{1,2}$, Yerkezhan Zhadykova ${ }^{1,2}$, Arman Khozhayev ${ }^{3}$, Dulat \\ Turebayevi,2, Dariyana Kulmirzayeva ${ }^{2,4}$, Saltanat Urazova ${ }^{1,2}$, Gaukhar \\ Nurtazinova $^{1,2}$, Yerlan Kuandykov ${ }^{2,5}$, Akmaral Amanshayeva ${ }^{2}$, Sauirbay \\ Sakhanov ${ }^{1,2}$, Zhanar Bukeyeva ${ }^{1,2}$, Vladimir Openko ${ }^{1,2}$, Serikbay Orazbayev ${ }^{1,2}$, Saken \\ Kozhakhmetov $^{1,2}$, Zarina Bilyalova ${ }^{2}$, Gulnur Igissinova ${ }^{2,3}$, Alireza Mosavi Jarrahi, \\ Nurbek Igissinov ${ }^{1,2,7 * *}$
}

\begin{abstract}
Background and objective: Colorectal cancer (CRC) remains one of the most widespread human malignancies. The aim of this study was to study trends of the incidence of CRC in Kazakhstan. Materials and Method: This retrospective study was done using descriptive and analytical methods of oncoepidemiology. Results: During the study period from 2009 to 2018, 28,950 new cases of CRC were recorded, 13,779 (47.6\%) cases were allocated to men and $15,171(52.4 \%)$ to women. It was found that the incidence rate of CRC increased from 14.79 (2009) to 17.72 in 2018 and the overall growth was 2.93 cases per 100,000. This increase was due to the age structure $-\sum \Delta_{\mathrm{A}}=+1.42$, the risk of acquiring illness $-\sum \Delta_{R}=+1.31$, and their combined effect $-\sum \Delta_{R A}=+0.20$. The component analysis results revealed that the increase in the number of patients with $\mathrm{CRC}$ was mainly due to the growth of the population $(\triangle \mathrm{P}=+37.7 \%)$, changes in age structure $\left(\Delta_{A}=+26.6 \%\right)$, and changes associated with the risk of acquiring illness $\left(\Delta_{R}=+24.6 \%\right)$. The number of patients (both sexes) was increasing in many regions largely due to the influence of the age structure of the population. In addition, it was found that growth in the number of patients in most regions, both men and women, was associated primarily with the risk of acquiring illness. Conclusion: The findings of the current study showed increasing trends in the incidence of CRC in all regions of the country. These changes were mainly influenced by demographic factors (population size and age structure), risk of acquiring the disease, and their combined effect.
\end{abstract}

Keywords: Colorectal cancer- incidence- trends- component analysis- Kazakhstan

Asian Pac J Cancer Prev, 22 (10), 3405-3414

\section{Introduction}

Colorectal cancer (CRC) remains one of the most widespread human malignancies. According to the International Agency for Research on Cancer, about 1.93 million new cases of CRC were registered in 2020 worldwide, and the age-standardized incidence rate (ASR) of CRC is 19.5 per 100,000 . About $50.3 \%$ of all new CRC cases occur in Asia and its incidence is 17.6 per 100,000 in this region (Ferlay et al., 2020A). According to Global Cancer Observation, the number of new CRC cases in the world will increase by $63 \%$ in 2040 (about 3.15M) (Ferlay et al., 2020B).

There is a wide geographic variation in CRC incidence (Ferlay et al.,2020) due to dietary characteristics (Baena and Salinas, 2015; Yang and Yu, 2018), bad habits
(Fliss-Isakov et al., 2018), environmental factors, and genetically driven susceptibility (Johnson et al., 2013; Gu et al.,2018; Keum and Giovannucci, 2019; Mattiuzzi et al., 2019).

In the recent decades, dietary and food consumption patterns of the population have changed (Chun et al., 2010; Kearney, 2010). For instance, there have been many changes in water consumption (Muckelbauer et al., 2016), food processing and storage technologies (Orlien and Bolumar, 2019), and the use of preservatives, stabilizers, aroma enhancers, synthetic dyes, and other food additives (Eskola et al., 2020).

In agriculture sector, different technologies are used to accelerate production of breeding material. In addition, hormonal drugs and antibiotics are used (Liu et al., 2017; Oliveira et al., 2020), most likely leading to a change in the

\footnotetext{
${ }^{1}$ Astana Medical University, Nur-Sultan, Kazakhstan. ${ }^{2}$ Central Asian Cancer Institute, Nur-Sultan, Kazakhstan. ${ }^{3}$ Department of Oncology, Asfendiyarov Kazakh National Medical University, Almaty, Kazakhstan. ${ }^{4}$ National Center for Neurosurgery, Nur-Sultan, Kazakhstan. ${ }^{5}$ Khoja Akhmet Yassawi International Kazakh-Turkish University, Turkistan, Kazakhstan. ${ }^{6}$ Cancer Research Center, Shahid Beheshti University of Medical Sciences, Tehran, Iran. ${ }^{7}$ Eurasian Institute for Cancer Research, Bishkek, Kyrgyzstan. *For Correspondence: n.igissinov@gmail.com
} 
normal human microbiota and malignant transformation of cells (Murphy et al., 2019).

CRC develops as a result of degeneration of adenomatous polyps (Lucas et al., 2017). Two of the main risk factors associated with CRS are hereditary (Mármol et al., 2017) and familial and factors (Valle, 2017; Boland et al., 2018). Other known predisposing factors include inflammatory bowel disease (ulcerative colitis, Crohn's disease) and the duration of the disease (Nadeem et al., 2020).

The overall incidence of CRC begins to increase approximately 8-10 years after the onset of inflammatory bowel disease and increases to $15-20 \%$ after 30 years (Eaden et al., 2001). The main risk factors are the duration of the disease, the prevalence of the lesion, young age, and the presence of complications (Dyson and Rutter, 2012). Age is a significant risk factor for the development of CRC. CRC is rare until the age of 40 , but the incidence of CRC increases in each subsequent decade and peaks at 60-75 years (Siegel et al., 2017).

The high frequency of CRC is attributed to low fiber, high animal protein, fat, and refined carbohydrate food content (Baena and Salinas, 2015). Obesity increases the risk of CRC by about 1.5 times or more in men (Dong et al., 2017). Alcohol consumption, smoking, and inherited colon diseases also increase the sporadic incidence of colon polyposis and CRC (Amitay et al., 2020).

Screening tests significantly reduce CRC incidence by detecting precancerous bowel disease or the cancer at early stage, allowing for timely medical treatment (Rex et al., 2017; Lauby-Secretan et al., 2018; Ladabaum et al., 2020). WHO recommends preventive examinations, namely doing fecal occult blood test every year from the age of 50. In case of a positive test result, a more detailed examination of the colon, such as colonoscopy, should be carried out (Winawer et al., 1995). Since 2011, screening for CRC has been carried out in Kazakhstan among the entire population aged 50 to 70 every two years using fecal occult blood test and colonoscopy procedure.

This is a continuation of several studies of the dynamics in malignant neoplasms incidence by the method of component analysis, we conducted studies in this direction earlier (Igissinov et al., 2012; Igissinov et al., 2013; Igissinov et al., 2015; Kuanyshkaliyeva et al., 2016; Igissinov et al., 2019), assessing the influence of demographic factors, risk factors and their combination at the same time, taking into account gender, ethnic groups in different localities. The aim of the study was to use principal components analysis to shed light on the dynamics of the incidence of CRC in Kazakhstan.

\section{Materials and Methods}

\section{Patient recruitment}

The cancer registry of the population of Kazakhstan covers 14 regions and cities of Almaty and Astana (now the city of Nur-Sultan). New cases of CRC were extracted from case report forms presented by the Ministry of Healthcare of the Republic of Kazakhstan (form 7 and form 35) from 2009 to 2018 (International Classification of Diseases - 10, , 10th Revision code C18-21).

\section{Population denominators}

The population of Kazakhstan was 18.2 million in 2018. Population denominators for the calculation of incidence rates from 2009 to 2018 were provided by the National Bureau of Statistics of Kazakhstan. At the same time, data on the number of populations of the republic, taking into account the studied regions, are used, all data are presented on the official website (Bureau of National Statistics, 2021).

\section{Statistical analysis}

Age-specific incidence rates (ASIRs) were calculated for eighteen different age groups $(0-4,5-9, \ldots, 80-84$, and $85+$ ) using the world standard population proposed by WHO (Ahmad et al., 2001) and according to the recommendations developed by the National Cancer Institute (NCI, 2013). The extensive, crude (CR) and ASIRs were determined based on the generally accepted methodology used in sanitary statistics Accordingly, the annual averages (M, P), mean error (m), Student criterion, $95 \%$ confidence interval $(95 \% \mathrm{CI})$, and average annual upward/downward rates (T, \%) were calculated (Merkov and Polyakov, 1974; Glanz, 1998; dos Santos Silva, 1999; Tango, 2010; Merabishvili, 2015). Trends were determined using the least squares method, and the average annual growth rates were calculated using the geometric mean.

The dynamics of indicators was investigated using component analysis according to methodological recommendations (Dvoyrin and Aksel, 1987; Chissov et al., 2007). The component method was used in this study to decompose the increase in the number of cases in the same population, but at different time periods. According to this method, 7 components of the increase in the number of cases were considered. The first 3 components were associated with changes in the population size, its age structure, and the combined influence of these factors. The true increase in the number of patients was due to the change only in the indicator of the risk of acquiring illness and was represented by the 4 th component. The next 3 components were associated with the risk of acquiring illness, an increase in the population, a change in its age structure, and the influence of all three factors. Thus, the last 4 components were associated with an increase in the risk of developing the disease. By "risk of acquiring illness", we meant the whole complex of reasons that could lead to an increase, decrease, or stabilization of the incidence.

Reviewing and processing of the received materials was carried out using the Microsoft 365 software package (Excel, Word, PowerPoint). In addition, online statistical calculators were used (https://medstatistic.ru/calculators/ averagestudent.html), where Student criterion was calculated when comparing the average values.

\section{Ethics approval}

Since this study involved the analysis of publicly available administrative data and did not involve contacting individuals, obtaining permission from an ethics committee was not required. 


\section{Results}

During the study period, 28,950 new cases of CRC were registered in the country $(13,779(47.6 \%)$ in men and 15,171 (52.4\%) in women). The highest proportion of CRC patients (both sexes) aged 60 to 69 years old (60-64 years old:15.9\% and 65-69 years old: $15.5 \%$ ) (Table 1).

Age-related indicators of the incidence of CRC (per $100,000)$ peaked in the age group of 75-79 years in both sexes (151.9 \pm 4.2 ) ( male :205.6 \pm 6.2 , female :124.7 \pm 4.2 ) (Table 1).

Trends of ASIR of CRC in the entire population tended to increase in almost all age groups, except for the age group of 40-44 years old ( $\mathrm{T}=-0.1 \%), 50-54$ years old $(\mathrm{T}=-0.7 \%)$, and $70-74$ years old $(\mathrm{T}=-0.2 \%)$. Trends of ASIR in the male population decreased in the age group of $75-79(\mathrm{~T}=-0.4 \%)$, and 85 , and older $(\mathrm{T}=-1.5 \%)$. In the female population, the age indicators decreased in the age group of 30-34 $(\mathrm{T}=-1.0 \%), 40-44(\mathrm{~T}=-1.9 \%), 50-54$ $(\mathrm{T}=-2.2 \%), 55-59(\mathrm{~T}=-0.7 \%)$, and $70-74(\mathrm{~T}=-0.6 \%)$. It should be noted that the value of the accuracy of the approximation of the listed decreases was not significant (Table 1).

Trends of age indicators generally affected the overall incidence rates, so the crude rate of CRC incidence in the total population of the country increased from 14.79 (2009) to 17.72 in $2018(\mathrm{p}=0.000)$, the total increase was 2.93 per 100,000 (Table 2) and depended on changes (per 100,000) in the age structure of the population $\left(\sum \Delta_{A}=+1.42\right)$, the risk of acquiring illness $\left(\sum \Delta_{R}=+1.31\right)$, and the combined influence of the risk of acquiring illness and the age structure $\left(\sum \Delta_{\mathrm{RA}}=+0.20\right)$. At the same time, the average annual growth rate of the aligned indicator was $\mathrm{T}=+2.0 \%$, and the approximation confidence value was close to $1\left(\mathrm{R}^{2}=0.7327\right)$.

In the male population of the republic, the CRC also increased from 14.69 (2009) to 17.69 in 2018 per 100,000 , indicating a statistically significant difference $(p=0.000)$. The overall increase $(+3.00$ per 100,000$)$ depended mainly on changes in the age structure of the population $\left(\sum \Delta_{\mathrm{A}}=+1.72\right)$ and the risk of acquiring illness $\left(\sum \Delta_{R}=+1.24\right)$. However, their combined effect was not pronounced $\left(\sum \Delta_{\mathrm{RA}}=+0.04\right)$ (Table 2$)$. The average annual growth crude incidence rate was $\mathrm{T}=+2.6 \%$ and the approximation value was $\mathrm{R}^{2}=0.7356$ (Table 1 ).

In the female population of the country, the overall increase $(+2.87)$ in crude incidence rates from 14.89 (2009) to 17.76 per 100,000 (2018) $(\mathrm{p}=0.000)$ depended on changes in the age structure of the population $\left(\sum \Delta_{A}=+1.20\right)$, the risk of acquiring illness $\left(\sum \Delta_{R}=+1.33\right)$, and the combined effect of the risk of acquiring illness and the age structure $\left(\sum \Delta_{\mathrm{RA}}=+0.34\right)\left(\mathrm{T}=+1.4 ; \mathrm{R}^{2}=0.5218\right)$ (Tables 1 and 2).

Furthermore, we used principal components analysis to shed light on the dynamics of the incidence of CRC in Kazakhstan (Tables 3 and 4). The results showed that the increase in the number of patients with $\mathrm{CRC}$ in the republic was associated with the influence of the following factors:

1. Growth of population number $\Delta \mathrm{P}=+37.7 \%$ (male $\Delta \mathrm{P}=+37.8 \%$; female $-\Delta \mathrm{P}=+37.5 \%$ ).

2. Changes in the age structure of the population $\Delta_{A}=+26.6 \%$ (male $-\Delta_{A}=+31.2 \%$; female $\left.-\Delta_{A}=+23.1 \%\right)$.

3. Combined effect of changes in population number and its age structure $\Delta_{\mathrm{PA}}=+3.6 \%$ (male $-\Delta_{\mathrm{PA}}=+4.4 \%$; female $-\Delta_{\mathrm{PA}}=+3.0 \%$ ).

4. Change in the risk of acquiring illness $\Delta_{\mathrm{R}}=+24.6 \%$ (male $-\Delta_{\mathrm{R}}=+22.5 \%$; female $-\Delta_{\mathrm{R}}=+25.7 \%$ ).

5. Combined effect of changes in the risk of acquiring illness and population number $\Delta_{\mathrm{RP}}=+3.3 \%$ ( male $-\Delta_{\mathrm{RP}}=+3.2 \%$; female $-\Delta_{\mathrm{RP}}=+3.4 \%$ ).

6. Combined effect of changes in the risk of acquiring illness and age structure of the population $\Delta_{\mathrm{RA}}=+3.7 \%$ (male $-\Delta_{\mathrm{RA}}=+0.7 \%$; female $-\Delta_{\mathrm{RA}}=+6.6 \%$ ).

7. Combined effect of the changes in the risk of acquiring illness, population number, and its age structure $\Delta_{R A} \mathrm{P}=+0.5 \%$ (male $-\Delta_{R A} \mathrm{P}=+0.1 \%$; female -

Table 1. Number and Age-Specific Incidence rate of CRC in Kazakhstan, 2009-2018

\begin{tabular}{|c|c|c|c|c|c|c|c|c|c|c|c|c|}
\hline \multirow[t]{3}{*}{ Age } & \multicolumn{4}{|c|}{ All } & \multicolumn{4}{|c|}{ Male } & \multicolumn{4}{|c|}{ Female } \\
\hline & \multirow[t]{2}{*}{ Number (\%) } & \multicolumn{3}{|c|}{ Incidence } & \multirow[t]{2}{*}{ Number (\%) } & \multicolumn{3}{|c|}{ Incidence } & \multirow[t]{2}{*}{ Number (\%) } & \multicolumn{3}{|c|}{ Incidence } \\
\hline & & per 100,000 & $\mathrm{~T}, \%$ & $\mathrm{R}^{2}$ & & per 100,000 & $\mathrm{~T}, \%$ & $\mathrm{R}^{2}$ & & per 100,000 & $\mathrm{~T}, \%$ & $\mathrm{R}^{2}$ \\
\hline$<30$ & $224(0.8)$ & $0.26 \pm 0.02$ & -1.6 & 0.0672 & $127(0.9)$ & $0.29 \pm 0.02$ & -1.6 & 0.0601 & $97(0.6)$ & $0.23 \pm 0.03$ & -1.5 & 0.0121 \\
\hline $30-34$ & $269(0.9)$ & $2.0 \pm 0.2$ & 0.4 & 0.0026 & $136(1.0)$ & $2.1 \pm 0.2$ & 1.8 & 0.0411 & $133(0.9)$ & $2.0 \pm 0.2$ & -1.0 & 0.0138 \\
\hline $35-39$ & 473 (1.6) & $4.0 \pm 0.2$ & 2.1 & 0.2455 & 233 (1.7) & $4.0 \pm 0.2$ & 0.2 & 0.0009 & $240(1.6)$ & $3.9 \pm 0.2$ & 4.0 & 0.4537 \\
\hline $40-44$ & $819(2.8)$ & $7.4 \pm 0.3$ & -0.1 & 0.0008 & $418(3.0)$ & $7.8 \pm 0.3$ & 1.6 & 0.1484 & 401 (2.6) & $7.0 \pm 0.4$ & -1.9 & 0.093 \\
\hline $45-49$ & $1381(4.8)$ & $13.0 \pm 0.4$ & 1.1 & 0.1374 & $674(4.9)$ & $13.3 \pm 0.6$ & 1.6 & 0.1089 & 707 (4.7) & $12.6 \pm 0.5$ & 0.6 & 0.0222 \\
\hline $50-54$ & $2558(8.8)$ & $25.5 \pm 0.7$ & -0.7 & 0.0565 & $1236(9.0)$ & $26.4 \pm 0.7$ & 1 & 0.1412 & $1322(8.7)$ & $24.7 \pm 1.1$ & -2.2 & 0.2749 \\
\hline $55-59$ & 3891 (13.4) & $47.4 \pm 1.1$ & 0.3 & 0.0129 & $1927(14.0)$ & $52.3 \pm 1.8$ & 1.3 & 0.1287 & 1964 (12.9) & $43.4 \pm 1.4$ & -0.7 & 0.0555 \\
\hline $60-64$ & 4614 (15.9) & $77.0 \pm 1.6$ & 0.3 & 0.0165 & $2273(16.5)$ & $89.7 \pm 3.1$ & 0.4 & 0.0165 & $2341(15.4)$ & $67.7 \pm 1.2$ & 0.1 & 0.0027 \\
\hline $65-69$ & 4488 (15.5) & $113.1 \pm 6.1$ & 3.7 & 0.4611 & 2189 (15.9) & $138.1 \pm 7.8$ & 4.7 & 0.6615 & $2299(15.2)$ & $96.7 \pm 5.5$ & 2.8 & 0.2401 \\
\hline $70-74$ & 4240 (14.6) & $128.2 \pm 2.4$ & -0.2 & 0.0091 & $1988(14.4)$ & $163.3 \pm 3.5$ & 0.4 & 0.0287 & $2252(14.8)$ & $107.8 \pm 2.3$ & -0.6 & 0.0788 \\
\hline $75-79$ & $3746(12.9)$ & $151.9 \pm 4.2$ & 0.3 & 0.0107 & $1696(12.3)$ & $205.6 \pm 6.2$ & -0.4 & 0.0201 & $2050(13.5)$ & $124.7 \pm 4.2$ & 1 & 0.0883 \\
\hline $80-84$ & $1648(5.7)$ & $127.5 \pm 5.7$ & 2.9 & 0.4099 & $644(4.7)$ & $169.5 \pm 10.2$ & 3.5 & 0.3262 & 1004 (6.6) & $110.0 \pm 5.1$ & 2.2 & 0.2263 \\
\hline $85+$ & $599(2.1)$ & $81.1 \pm 3.7$ & 0.1 & 0.0009 & $238(1.7)$ & $131.6 \pm 9.4$ & -1.5 & 0.0431 & $361(2.4)$ & $64.8 \pm 4.5$ & 0.5 & 0.0046 \\
\hline CR & $28950(100.0)$ & $16.9 \pm 0.4$ & 2 & 0.7327 & $13779(100.0)$ & $16.7 \pm 0.5$ & 2.6 & 0.7356 & $15171(100.0)$ & $17.2 \pm 0.3$ & 1.4 & 0.5218 \\
\hline ASR & & $18.1 \pm 0.3$ & 1 & 0.3182 & & $21.9 \pm 0.5$ & 1.4 & 0.4062 & & $15.9 \pm 0.1$ & 0.4 & 0.0724 \\
\hline
\end{tabular}

$\mathrm{T}$, average annual upward/downward rates; $\mathrm{R}^{2}$, the value of the approximation confidence; $\mathrm{CR}$, crude rate; ASR, age-standardized rate 
Table 2. Component Analysis of CRC Incidence Growth in Kazakhstan, 2009-2018

\begin{tabular}{|c|c|c|c|c|c|c|c|c|c|}
\hline \multirow{3}{*}{$\begin{array}{l}\text { Age group } \\
\text { (i) }\end{array}$} & \multirow{2}{*}{\multicolumn{2}{|c|}{$\begin{array}{l}\text { Age structure } \\
\quad\left(S i j=\frac{N_{i j}}{N_{j}}\right.\end{array}$}} & \multirow{3}{*}{$\begin{array}{c}\text { Growth of } \\
\text { structural } \\
\text { indicators } \\
\left(S_{i 2}-S_{i 1}\right) \\
(3)-(2)\end{array}$} & \multirow{2}{*}{\multicolumn{2}{|c|}{ Incidence, per 100,000}} & \multicolumn{4}{|c|}{ Incidence growth, per 100,000} \\
\hline & & & & & & \multirow{2}{*}{$\begin{array}{c}\text { General } \\
\left(P_{i 2}-P_{i 1}\right) \\
(6)-(5)\end{array}$} & \multicolumn{3}{|c|}{ Including due to changes of } \\
\hline & $\begin{array}{c}2009 \\
\left(S_{i 1}\right)\end{array}$ & $\begin{array}{c}2018 \\
\left(S_{i 2}\right)\end{array}$ & & $\begin{array}{l}2009 \\
\left(P_{i 1}\right)\end{array}$ & $\begin{array}{l}2018 \\
\left(P_{i 2}\right)\end{array}$ & & $\begin{array}{c}\Delta_{\mathrm{A}} \\
(4) \times(5)\end{array}$ & $\begin{array}{c}\Delta_{\mathrm{R}} \\
(2) \times(7)\end{array}$ & $\begin{array}{c}\Delta_{\mathrm{RA}} \\
(4) \times(7)\end{array}$ \\
\hline 1 & 2 & 3 & 4 & 5 & 6 & 7 & 8 & 9 & 10 \\
\hline \multicolumn{10}{|l|}{ Both sexes } \\
\hline$<30$ & 0.5217 & 0.5011 & $-0,0206$ & 0.29 & 0.23 & $-0,06$ & $-0,006$ & $-0,031$ & $+0,001$ \\
\hline $30-34$ & 0.0761 & 0.0837 & 0.0075 & 1.97 & 2.5 & 0.53 & 0.015 & 0.04 & 0.004 \\
\hline $35-39$ & 0.0711 & 0.0699 & -0.0012 & 3.35 & 4.34 & 0.99 & -0.004 & 0.07 & -0.001 \\
\hline $40-44$ & 0.0669 & 0.0634 & -0.0036 & 6.82 & 8.35 & 1.52 & -0.024 & 0.102 & -0.005 \\
\hline $45-49$ & 0.0689 & 0.0589 & -0.0100 & 13.25 & 13.08 & -0.17 & -0.133 & -0.011 & 0.002 \\
\hline $50-54$ & 0.0552 & 0.0559 & 0.0008 & 22.12 & 25.11 & 2.99 & 0.017 & 0.165 & 0.002 \\
\hline $55-59$ & 0.0432 & 0.0541 & 0.0109 & 46.51 & 45.84 & -0.66 & 0.506 & -0.029 & -0.007 \\
\hline $60-64$ & 0.0256 & 0.0399 & 0.0143 & 75.78 & 75.45 & -0.32 & 1.086 & -0.008 & -0.005 \\
\hline $65-69$ & 0.0252 & 0.0295 & 0.0043 & 79.89 & 111.19 & 31.3 & 0.344 & 0.789 & 0.135 \\
\hline $70-74$ & 0.0227 & 0.0144 & -0.0083 & 127.66 & 122.18 & -5.48 & -1.061 & -0.124 & 0.046 \\
\hline $75-79$ & 0.0117 & 0.0159 & 0.0042 & 130.22 & 137.95 & 7.73 & 0.542 & 0.091 & 0.032 \\
\hline $80-84$ & 0.0082 & 0.0086 & 0.0004 & 125.41 & 158.03 & 32.62 & 0.049 & 0.267 & 0.013 \\
\hline $85+$ & 0.0034 & 0.0048 & 0.0013 & 72.63 & 65.77 & -6.86 & 0.096 & -0.024 & -0.009 \\
\hline Total & $\sum S_{i I}=1.0$ & $\sum S_{i 2}=1.0$ & & $P_{I}=14.79$ & $P_{2}=17.72$ & 2.93 & $\Sigma A_{A}=+1.42$ & $\Sigma A_{R}=+1.31$ & $\sum \Delta_{R A}=+0.20$ \\
\hline \multicolumn{10}{|c|}{ Male* } \\
\hline Total & $\sum S_{i l}=1.0$ & $\sum S_{i 2}=1.0$ & & $P_{1}=14.69$ & $P_{2}=17.69$ & 3 & $\sum A_{A}=+1.72$ & $\sum \Delta R=+1.24$ & $\sum \Delta_{R A}=+0.04$ \\
\hline \multicolumn{10}{|c|}{ Female* } \\
\hline Total & $\sum S_{i l}=1.0$ & $\sum S_{i 2}=1.0$ & & $P_{I}=14.89$ & $P_{2}=17.76$ & 2.87 & $\sum A_{A}=+1.20$ & $\sum \Delta_{R}=+1.33$ & $\sum \Delta_{R A}=+0.34$ \\
\hline
\end{tabular}

$\Delta_{\mathrm{A}}$, the age structure of the population; $\Delta_{\mathrm{R}}$, risk of acquiring illness; $\Delta_{\mathrm{RA}}$, risk of acquiring illness and age structure of the population; $*$ The calculations were made in the same way as for the entire population.

$\left.\Delta_{\mathrm{RA}} \mathrm{P}=+0.9 \%\right)$

The total increase in the absolute number of new cases of CRC (both sex) was equal to the sum of the components: $\mathrm{n} 2-\mathrm{n} 1=322+227+31+210+29+32+4=854$ or $+36.1 \%$ (Table 4 ) in comparison with the primary number of patients $(854 \div 2364 \times 100=36.1 \%)$. Accordingly, the components of the increase as a percentage of the initial level was equal to:

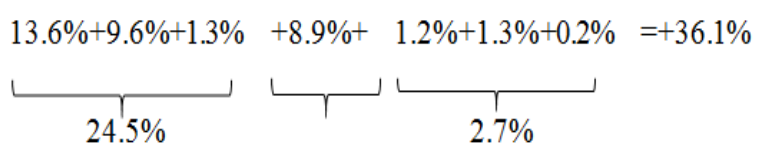

Thus, CRC (both sexes) was characterized by an increase in the number of cases because of the changes in the total population size and its structure $(24.5 \%$ of the total increase of $36.1 \%)$. The real increase in the number of cases (risk of acquiring illness) was $\Delta_{\mathrm{R}}=+8.9 \%$.

The increase in new cases of CRC in men and women is presented in Table 4, indicating no significant difference with respect to sex.

It should be noted that during the study period, the number of patients (both sexes) in the country increased by $36.1 \%$ (from 2,364 to 3,218 ), which was higher than the estimation obtained by the component analysis ($2,945)$ (Table 3). The increase was due to demographic factors $\left(\Delta_{\mathrm{P}}+\mathrm{A}+\mathrm{P}_{\mathrm{A}}=+67.8 \%\right)$ and the combined influence of risk factors for acquiring illness with demographic components $\left(\Delta_{\mathrm{R}}+\mathrm{R}_{\mathrm{P}}+\mathrm{R}_{\mathrm{A}}+\mathrm{R}_{\mathrm{AP}}=+32.2 \%\right)$. In men, the influence of demographic factors was slightly more pronounced $\left(\Delta_{\mathrm{P}}+\mathrm{A}+\mathrm{P}_{\mathrm{A}}=+73.5 \%\right)$, while the combined influence of risk factors and demographic factors was less pronounced $\left(\Delta_{\mathrm{R}}+\mathrm{R}_{\mathrm{P}}+\mathrm{R}_{\mathrm{A}}+\mathrm{R}_{\mathrm{AP}}=+26.5 \%\right)$. Among women, the impact of demographic indicators led to an increase in patients $\left(\Delta_{\mathrm{P}}+\mathrm{A}+\mathrm{P}_{\mathrm{A}}=+63.5 \%\right)$, and the combined influence of risk factors and changes in demographic indicators also played a role $\left(\Delta_{\mathrm{R}}+\mathrm{R}_{\mathrm{P}}+\mathrm{R}_{\mathrm{A}}+\mathrm{R}_{\mathrm{AP}}=+36.5 \%\right)$.

The dynamics of the incidence of CRC had regional characteristics. So that, in the Kostanay region, there was an overall increase $(+9.42)$ in the incidence of CRC (per $100,000)$ in the entire population, from 23.02 in 2009 to 32.43 in $2018(\mathrm{p}=0.000)$ (Table 5), which primarily depended on the risk of acquiring illness $\left(\sum \Delta_{R}=+5.63\right.$ per $100,000)$ and secondly on changes in the age structure of the population $\left(\sum \Delta_{\mathrm{A}}=+3.89\right.$ per 100,000$)$. In contrast, the combined effect of the age structure and the risk of acquiring illness reduced this indicator $\left(\sum \Delta_{\mathrm{RA}}=-0.11\right.$ per 100,000$)$. At the same time, the average annual growth rate of the aligned indicator was $\mathrm{T}=+3.0 \%$, and the confidence value of the approximation was equaled to $R^{2}=0.5708$. Having studies the role of various components, it was found (Table 5) that the incidence of new cases in this region was associated with demographic factors $\left(\Delta_{\mathrm{P}}+\mathrm{A}+\mathrm{P}_{\mathrm{A}}=+39.5 \%\right)$ and the complex influence of the risk of acquiring illness $\left(\Delta_{R}=+62.4 \%\right)$ with the components of the population size, its age structure, and 
Table 3. Component Analysis of the Dynamics of CRC Incidence in Kazakhstan from 2009 till 2018

\begin{tabular}{|c|c|c|c|c|c|c|c|c|c|}
\hline \multirow{2}{*}{$\begin{array}{l}\text { Age } \\
\text { group } \\
\text { (i) }\end{array}$} & \multicolumn{2}{|c|}{ Number $\left(n_{i j}\right)$} & \multicolumn{2}{|c|}{ Population number $\left(N_{i j}\right)$} & \multicolumn{2}{|c|}{ Crude incidence $\left(P_{i j}{ }^{C}\right)$} & \multicolumn{2}{|c|}{ Standardized } & \multirow{2}{*}{$\begin{array}{c}\text { END in } 2018 \\
\left(P_{i j} N_{i 2} 10^{-5}\right) \\
(6) \times(5) \times 10^{-5}\end{array}$} \\
\hline & $2009(j=1)$ & $2018(j=2)$ & $2009(j=1)$ & $2018(j=2)$ & $2009(j=1)$ & $2018(j=2)$ & $2009(j=1)$ & $2018(j=2)$ & \\
\hline 1 & 2 & 3 & 4 & 5 & 6 & 7 & 8 & 9 & 10 \\
\hline \multicolumn{10}{|c|}{ Both sex } \\
\hline$<30$ & 24 & 21 & 8338308 & 9099474 & 0.29 & 0.23 & & 0.12 & 26.2 \\
\hline $30-34$ & 24 & 38 & 1216653 & 1519070 & 1.97 & 2.5 & & 0.19 & 30 \\
\hline $35-39$ & 38 & 55 & 1135971 & 1268564 & 3.35 & 4.34 & & 0.308 & 42.4 \\
\hline $40-44$ & 73 & 96 & 1069726 & 1150288 & 6.82 & 8.35 & & 0.559 & 78.5 \\
\hline $45-49$ & 146 & 140 & 1101902 & 1070014 & 13.25 & 13.08 & & 0.902 & 141.8 \\
\hline $50-54$ & 195 & 255 & 881544 & 1015469 & 22.12 & 25.11 & & 1.385 & 224.6 \\
\hline $55-59$ & 321 & 450 & 690245 & 981581 & 46.51 & 45.84 & & 1.98 & 456.5 \\
\hline $60-64$ & 310 & 547 & 409084 & 724939 & 75.78 & 75.45 & & 1.931 & 549.4 \\
\hline $65-69$ & 322 & 596 & 403032 & 536021 & 79.89 & 111.19 & & 2.804 & 428.3 \\
\hline $70-74$ & 463 & 319 & 362684 & 261088 & 127.66 & 122.18 & & 2.773 & 333.3 \\
\hline $75-79$ & 244 & 398 & 187376 & 288503 & 130.22 & 137.95 & & 1.617 & 375.7 \\
\hline $80-84$ & 164 & 246 & 130769 & 155662 & 125.41 & 158.03 & & 1.293 & 195.2 \\
\hline $85+$ & 40 & 57 & 55076 & 86664 & 72.63 & 65.77 & & 0.227 & 62.9 \\
\hline Total & $n_{1}=2364$ & $n_{2}=3218$ & $N_{l}=15982370$ & $N_{2}=18157337$ & $P_{I}=14.79$ & $P_{2}=17.72$ & $P_{l}^{C}=14.79$ & $P_{2}^{C}=16.09$ & $E\left(n_{2}\right)=2945$ \\
\hline Growth & \multicolumn{2}{|c|}{$\frac{n_{1}-n_{2}}{n_{1}} 100=36.1$} & \multicolumn{2}{|c|}{$\frac{N_{1}-N_{2}}{N_{1}} 100=13.6$} & \multicolumn{2}{|c|}{$\frac{P_{1}-P_{2}}{P_{1}} 100=19.8$} & \multicolumn{2}{|c|}{$\frac{P_{1}^{c}-P_{2}^{c}}{P_{1}^{c}} 100=8.8$} & \\
\hline \multicolumn{10}{|c|}{ Male* } \\
\hline Total & $n_{l}=1131$ & $n_{2}=1555$ & $N_{l}=7698875$ & $N_{2}=8791298$ & $P_{I}=14.69$ & $P_{2}=17.69$ & $P_{l}^{C}=14.69$ & $P_{2}^{C}=15.93$ & $\left.\mathrm{E}\left(n_{2}\right)\right)=1443$ \\
\hline Growth & $\frac{n_{1}-n_{2}}{n_{1}} 1$ & $=37.5$ & $\frac{N_{1}-N_{2}}{N_{1}} 1$ & $=14.2$ & $\frac{P_{1}-P_{2}}{P_{1}}$ & $0=20.4$ & $\frac{P_{1}^{c}-P_{2}^{c}}{P_{1}^{c}}$ & $100=8.4$ & \\
\hline \multicolumn{10}{|c|}{ Female* } \\
\hline Total & $n_{1}=1233$ & $n_{2}=1663$ & $N_{l}=8283495$ & $N_{2}=9366039$ & $P_{I}=14.89$ & $P_{2}=17.76$ & $P_{l}^{C}=14.89$ & $P_{2}^{C}=16.22$ & $\mathrm{E}\left(n_{2}\right)=1506$ \\
\hline Growth & $\frac{n_{1}-n_{2}}{n_{1}} 1$ & $=34.9$ & $\frac{N_{1}-N_{2}}{N_{1}} 1$ & $=13.1$ & $\frac{P_{1}-P_{2}}{P_{1}}$ & $=19.3$ & $\frac{P_{1}^{c}-P_{2}^{c}}{P_{1}^{c}}$ & $100=9.0$ & \\
\hline
\end{tabular}

END, the expected number of diseases; *, The calculations were made in the same way as for the entire population.

the influence of all the three above-mentioned factors $\left(\Delta_{\mathrm{R}}+\mathrm{R}_{\mathrm{P}}+\mathrm{R}_{\mathrm{A}}+\mathrm{R}_{\mathrm{AP}}=+60.5 \%\right)$.

Following the analysis of the average annual growth rate of aligned indicators of $\mathrm{CRC}$ incidence in the entire population, it was detected that the most pronounced growth was in the Akmola $\left(\mathrm{T}=+4.7 \% ; \mathrm{R}^{2}=0.7630\right)$ and Atyrau regions $\left(\mathrm{T}=+5.4 \% ; \mathrm{R}^{2}=0.6244\right)$. This growth was statistically significant in 2018 in comparison with 2009, and the values of the accuracy of the approximation were pronounced (Table 5).

Regarding the influence of various components with respect to region for the entire population (Table 5), it was found that there was a pronounced decrease in the North Kazakhstan region $\left(\Delta_{\mathrm{P}}=-121.7 \%\right)$ due to changes in the population size, and the largest increase was allocated to Almaty city $\left(\Delta_{\mathrm{p}}=+98.6 \%\right)$. The role of the influence of age structure in the increase in the number of patients was positive in all regions, but it was mostly pronounced in the Pavlodar $\left(\Delta_{\mathrm{A}}=+281.6 \%\right)$ and North Kazakhstan $\left(\Delta_{\mathrm{A}}=+373.0 \%\right)$ regions. The combined effect of changes in the population size and its age structure showed a decline only in the North Kazakhstan region $\left(\Delta_{\mathrm{PA}}=-24.3 \%\right)$, while there was an increase in other regions, especially in Kyzylorda $\left(\Delta_{\mathrm{PA}}=+9.1 \%\right)$ and Mangystau $\left(\Delta_{\mathrm{PA}}=+10.3 \%\right)$ regions, as well as in Astana city $\left(\Delta_{\mathrm{PA}}=+9.9 \%\right)$. The decrease in the absolute number of patients with CRC due to the risk of acquiring illness was most pronounced in North Kazakhstan $\left(\Delta_{\mathrm{R}}=-180.4 \%\right)$ and Pavlodar $\left(\Delta_{R}=-274.6 \%\right)$ regions, and the maximum increase was found in Atyrau $\left(\Delta_{R}=+53.2 \%\right)$, Almaty $\left(\Delta_{R}=+53.5 \%\right)$, and Kostanay $\left(\Delta_{R}=+62.4 \%\right)$ regions. A pronounced increase in the combined impact of the risk of acquiring illness and the population size was found in Atyrau $\left(\Delta_{\mathrm{RP}}=+11.7 \%\right)$ and North Kazakhstan $\left(\Delta_{\mathrm{RP}}=+11.8 \%\right)$ regions. Changes in the risk of acquiring illness and the age structure led to a sharp decrease in the number of patients in the North Kazakhstan region $\left(\Delta_{\mathrm{RA}}=-169.4 \%\right)$, and the maximum rise was noted in Pavlodar region $\left(\Delta_{\mathrm{RA}}=+55.1 \%\right)$. In the North Kazakhstan region, the increase in the number of patients was highest compared to other regions due to the combined influence of the risk of acquiring illness, population size, and age structure $\left(\Delta_{\mathrm{RA}} \mathrm{P}=+11.0 \%\right)$.

In a nutshell, the component analysis revealed geographical variability in the dynamics of the number of patients and the incidence of CRC in Kazakhstan, which was associated with a difference in the influence of 
Table 4. Influencing Components on the Number of Cases of CRC in Kazakhstan

\begin{tabular}{|c|c|c|c|c|c|c|c|c|c|}
\hline \multirow[t]{3}{*}{ Components of growth in the number of cases due to: } & \multicolumn{3}{|c|}{ Both sexes } & \multicolumn{3}{|c|}{ Male } & \multicolumn{3}{|c|}{ Female } \\
\hline & AN & $\%$ growth & & AN & $\%$ growth & & $\mathrm{AN}$ & $\%$ growth & \\
\hline & & to $\left(n_{2}-n_{1}\right)$ & to $n_{1}$ & & to $\left(n_{2}-n_{1}\right)$ & to $n_{1}$ & & to $\left(n_{2}-n_{l}\right)$ & to $n_{1}$ \\
\hline 1. Growth PN $\Delta_{P}=\frac{N_{\mathbf{1}}-N_{\mathbf{2}}}{\boldsymbol{N}_{\mathbf{1}}} n_{\mathbf{1}}$ & 322 & 37.7 & 13.6 & 160 & 37.8 & 14.2 & 161 & 37.5 & 13.1 \\
\hline 2. Changes ASP $\Delta_{\boldsymbol{A}}=\frac{\boldsymbol{N}_{\mathbf{1}}}{\boldsymbol{N}_{\mathbf{2}}}\left(\boldsymbol{E}\left(\boldsymbol{n}_{\mathbf{2}}\right)-\boldsymbol{n}_{\mathbf{2}}-\Delta_{H}\right.$ & 227 & 26.6 & 9.6 & 132 & 31.2 & 11.7 & 99 & 23.1 & 8 \\
\hline \multirow[t]{2}{*}{ 3. Combined effect of changes in PN and ASP $\Delta_{P A}=\frac{N_{2}-N_{1}}{N_{1}} \Delta_{A}$} & 31 & 3.6 & 1.3 & 19 & 4.4 & 1.7 & 13 & 3 & 1.1 \\
\hline & \multicolumn{3}{|c|}{$\sum 1-3=+67.8 \sum 1-3=+24.5$} & \multicolumn{3}{|c|}{$\sum 1-3=+73.5 \sum 1-3=+27.6$} & \multicolumn{3}{|c|}{$\sum 1-3=+63.5 \sum 1-3=+22.2$} \\
\hline 4. Change of RAI $\Delta_{R}=\boldsymbol{N}_{\mathbf{1}}\left(P_{2}^{c}-P_{1}^{c}\right) \times \mathbf{1 0}^{-\mathbf{5}}$ & 210 & 24.6 & 8.9 & 95 & 22.5 & 8.4 & 110 & 25.7 & 9 \\
\hline 5. Combined effect of changes of RAI and PN $\Delta_{R P}=\frac{N_{2}-N_{1}}{N_{1}} \Delta_{R}$ & 29 & 3.3 & 1.2 & 14 & 3.2 & 1.2 & 14 & 3.4 & 1.2 \\
\hline 6. Combined effect of changes of RAI and ASP $\Delta_{R A}=\frac{N_{2}-N_{1}}{N_{1}} \Delta_{R}$ & 32 & 3.7 & 1.3 & 3 & 0.7 & 0.3 & 28 & 6.6 & 2.3 \\
\hline 7. Combined effect of the changes RAI, PN and ASP & 4 & 0.5 & 0.2 & 0 & 0.1 & 0.04 & 4 & 0.9 & 0.3 \\
\hline
\end{tabular}

AN, absolute number; PN, population number; ASP, age structure of the population; RAI, risk of acquiring illness

demographic factors (changes in population size, its age structure) and the risk of acquiring illness (i.e., a set of reasons that led to an increase, decrease, or stabilization of the rates).

\section{Discussion}

The results of this study showed that the incidence rate of CRC was as high as 16.9 cases per 100,000 in Kazakhstan, while the difference between men (16.7) and women (17.2) was not statistically significant in this regard. However, it was found that the ASRs was significantly higher in men (21.9) than women (15.9). Generally, the ASRs of the CRC was 18.1 cases per 100,00 , revealing that Kazakhstan is moving into a zone of high incidence (Ferlay et al., 2020a). In terms of gender, the lowest rates in men was reported (per 100,000) in Mozambique (3.6) and Burkina Faso (3.6), and in women were reported in Bhutan (1.9) and Tajikistan (2.9). The highest rates of $\mathrm{CRC}$ in men were found in Slovakia (60.7) and Hungary (62.0), and in women were found in Denmark (35.6) and Norway (38.7) (Ferlay et al., 2020a).

The results on age-related incidence indicators in the country had high values in patients over 65 years of age. Similar results were found in French Polynesia (111.2 per 100,000), Jordan (114.8), Georgia (120.2), and United Arab Emirates (122.5). This pattern was repeated in men population and there were alike indicators in Saint Lucia (140.7), Qatar (141.2), Paraguay (147.9), and Costa Rica (147.5). Whereas in women, we saw changes similar to French Polynesia (96.4), Georgia (99.6), Venezuela (100.5), and Bahrain (101.2) (Ferlay et al., 2020A).
The results of the epidemiological study regarding CRC in Kazakhstan for 2004-2014 (Abdullayev et al., 2017) showed an increase in its incidence with stable trends, which was in line with our study. At the same time, there was an increase in the number of patients at stages I and II, which could be due to the influence of screening.

The incidence of CRC in Kazakhstan had increasing trend, which could be due to the impact of ongoing anti-cancer measures, including screening. Thus, according to Zhylkaidarova (2021), changes in morbidity can be estimated through the assessment of the impact of screening. Herewith, the regions that got a score of 0-2 points, according to our data, had a low degree of approximation reliability (i.e., changes in the trends were not significant). Our study revealed following results: Almaty city ( 0 points; $\left.\mathrm{R}^{2}=0.3475\right)$, North Kazakhstan $(0$ points; $\mathrm{R}^{2}=0.0649$ ), West Kazakhstan ( 1 point; $\left.\mathrm{R}^{2}=0.4035\right)$, Pavlodar ( 1 point; $\mathrm{R}^{2}=0.4236$ ), Kyzylorda ( 2 points; $\left.\mathrm{R}^{2}=0.0999\right)$, and Mangistau ( 2 points; $\left.\mathrm{R}^{2}=0.1759\right)$. Akmola ( 3 points; $\mathrm{R}^{2}=0.7630$ ), Kazakhstan (3 points; $\left.\mathrm{R}^{2}=0.7327\right)$, Aktobe ( 4 points; $\left.\mathrm{R}^{2}=0.6006\right)$, Karaganda (4 points; $\left.\mathrm{R}^{2}=0.5941\right)$, Kostanay ( 4 points; $\mathrm{R}^{2}=0.5708$ ), and South Kazakhstan ( 4 points; $\mathrm{R}^{2}=0.5674$ ) had a significant degree of approximation. In Atyrau $\left(\mathrm{R}^{2}=0.6244\right)$ and East Kazakhstan $\left(\mathrm{R}^{2}=0.6502\right)$, the degrees of approximation were significant. In Almaty $\left(\mathrm{R}^{2}=0.2823\right)$, Zhambyl region $\left(\mathrm{R}^{2}=0.1656\right)$, and Astana city $\left(\mathrm{R}^{2}=0.0384\right)$, the degrees of accuracy of the approximation were not very pronounced, especially in the capital. These findings could be due to this fact that the authors did not study the growth rates of the dynamic series but compared the initial and final data of the studied period. 


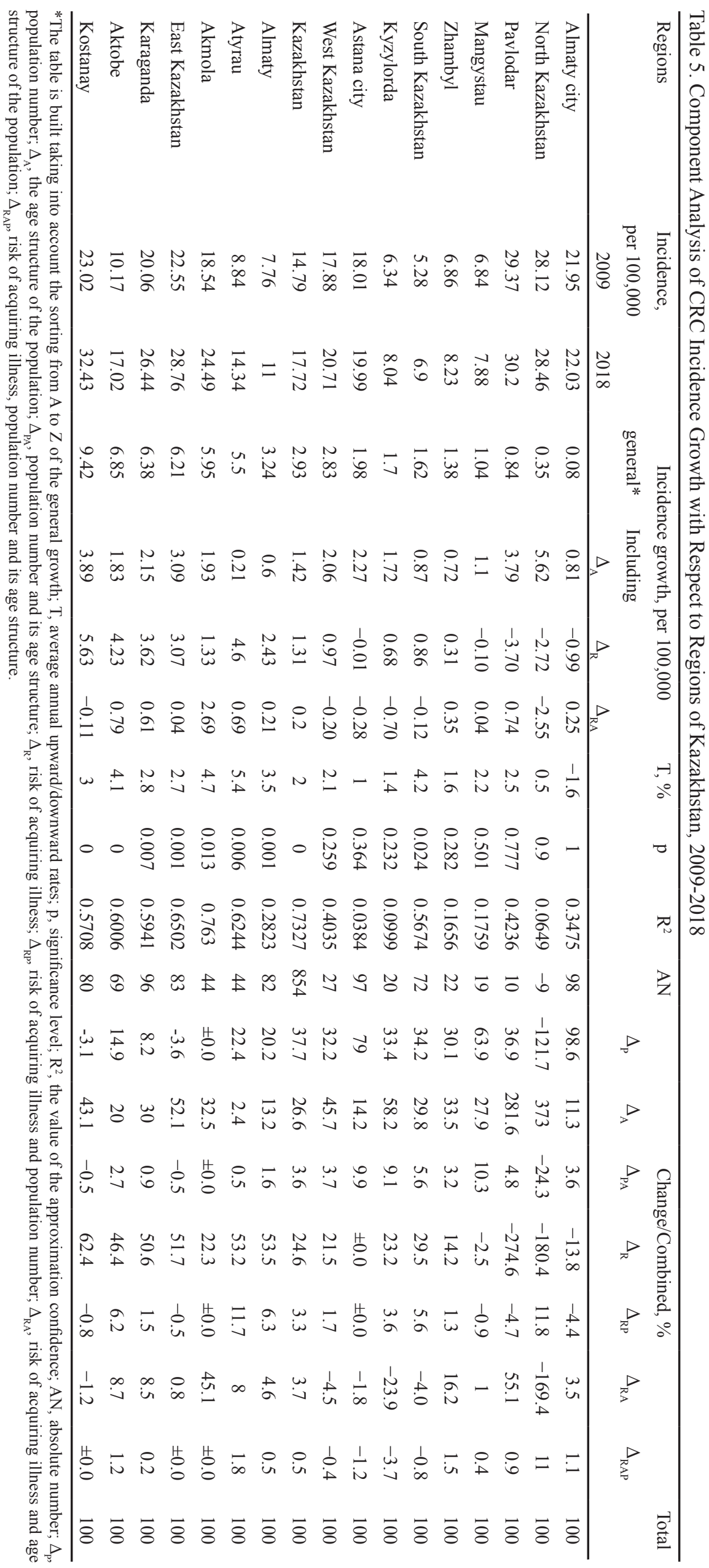


Having investigated the effectiveness of screening programs in the Almaty region for 2018-2020 (Zholmurzayeva et al., 2021), it was revealed that $t$ the average response rate was $50 \%$ for the first step of screening and very low for the second step. At the same time, it should be noted that according to the data of medical and preventive institutions of the Almaty region, there was no excess load of the available endoscopic equipment. Consequently, the reasons for the insufficient response and screening were not related to the material problems of the healthcare system but to low social mobilization, which was similar to the findings of a study by Heisser (2021).

The results of our studies showed a unimodal increase in age indicators, which peaked at the age group of 75-79 years, and its incidence in this age group of men was almost twice as high. CRC incidence in the world in the age groups of 70 years and older was highest in Denmark (389.8 per 100,000 - both gender; 476.7 - male; 319.7 - female), Netherlands (390.9; 492.0; 306.1), and Norway (421.3; 473.3; 376.7) (Ferlay et al., 2020A).

With respect to gender-related differences, according to randomized study (Bull et al., 2020), higher BMI increases the risk of CRC among men, while higher waist-to-hip ratio considerably raises CRC risk among women. White et al., (2018) revealed that men were more prone to get CRC than women, though they see no gender differences in diagnosis for advanced stages of disease. Alongside this, the male population is more susceptible to a number of modifiable risk factors, such as smoking and alcohol intake (Rawla et al., 2019).

Declining trends of age indicators in women aged under 30, 30-34, 40-44, 50-59, 70-74 years old were notable. In other words, there was no increase in the diagnosis of this disease especially in screening target group (50-75 years). This phenomenon may be due to insufficient social mobilization, which needs health managers' more attention. Meanwhile, a previous study revealed an association between reduction of morbidity and mortality and performing colonoscopy (Brown et al., 2021). They found that during the screening measures, there was a temporary increase (between 2002-2007) in CRC incidence, but in general (between 2000-2016), morbidity and mortality rates were declined. Authors consider such changes as expected ones because of detection of patients at early stage of CRC.

These findings can be attributed to the timely diagnosis and treatment of precancerous diseases. As in a previous study, a decrease in the incidence of CRC in the group subject to screening (50-74 year) was reported. The authors of aforementioned study attributed this phenomenon to the important role of screening in removal of adenomas and its notable effect on CRC incidence (Clark et al., 2020).

The formation and impact of the studied factors in regions were dissimilar. The analysis of data on the CRC incidence with respect to region showed that there were certain regions where the component of "risk of acquiring illness" had no effect. However, we found the presence of certain problems in the organization of anti-cancer measures, including screening.

In general, an increase in the incidence of CRC was noted in many regions, where this growth was due to the greater influence of the "risk of acquiring illness" component. It influenced the formation of the general trend in the country as a whole resulting from anti-cancer measures in CRC, including screening. Unfortunately, it was not possible to compare our component analysis results with the literature data due to the lack of research in this direction.

The results of component analysis indicated of the efficacy of anti-cancer measures, including CRC screening, in the country, while the influence of other exogenous and endogenous factors were not excluded.

\section{Author Contribution Statement}

DM, AA, SS, YK, GN - Collection and preparation of data, primary processing of the material and their verification.

DM, SU, YZ, VO, NI - Statistical processing and analysis of the material, writing the text of the article (material and methods, results).

DM, SK, DT, ZB, GI, ZhB, SO - Writing the text of the article (introduction, discussion).

NI, AMJ, DM - Concept, design and control of the research, approval of the final version of the article. All authors approved the final version of the manuscript.

\section{Acknowledgments}

The authors greatly appreciate the contribution of the Ministry of Healthcare of the Republic of Kazakhstan to the current research by providing the data.

This study was not funded. It was part of Dana Mauyenova's $\mathrm{PhD}$ dissertation, which was approved at the University Council of Astana Medical University.

\section{Conflict of Interest}

The authors declare that there is no conflict of interest.

\section{References}

Abdullayev MS, Nurgaziyev KS, Zhylkaydarova AZ, Mansurova AB (2017). Epidemiological aspects of colorectal cancer in Kazakhstan. Surgery news, 25, 394-403.

Ahmad OB, Boschi-Pinto C, Lopez AD, et al (2001). Age standardization of rates: a new who standard. GPE Discussion Paper Series: No.31 EIP/GPE/EBD. World Health Organization; 2001 [cited 2021 Apr 15]. Available from: https://www.who.int/healthinfo/paper31.pdf

Amitay EL, Carr PR, Jansen L, et al (2020). Smoking, alcohol consumption and colorectal cancer risk by molecular pathological subtypes and pathways. $B r J$ Cancer, 122, 1604-10.

Baena R, Salinas P (2015). Diet and colorectal cancer. Maturitas, 80, 258-64.

Boland PM, Yurgelun MB, Boland CR (2018). Recent progress in Lynch syndrome and other familial colorectal cancer syndromes. CA Cancer J Clin, 68, 217-31.

Brown JJ, Asumeng CK, Greenwald D, et al (2021). Decreased colorectal cancer incidence and mortality in a diverse urban population with increased colonoscopy screening. $B M C$ Public Health, 21, 1280.

Bull CJ, Bell JA, Murphy N, et al (2020). Adiposity, metabolites, 
and colorectal cancer risk: Mendelian randomization study. BMC Med, 18, 396.

Bureau of National Statistics of the Agency for Strategic Planning and Reforms of the Republic of Kazakhstan (2021) [cited $2021 \mathrm{Feb} 25$ ]. Available from official website of the: https://stat.gov.kz/.

Chissov V, Starinskiy V, Kovalev B (2007). The organization of oncological service in Russia (methodical recommendations, manuals for doctors). Moscow, 663 p. (Russian).

Chun OK, Chung CE, Wang Y, Padgitt A, Song WO (2010). Changes in intakes of total and added sugar and their contribution to energy intake in the U.S. Nutrients, 2, 834-54.

Clark GR, Anderson AS, Godfrey TG, et al (2020). Variation in changes in the incidence of colorectal cancer by age and association with screening uptake: an observational study. BMJ Open, 10, e037925.

Dong Y, Zhou J, Zhu Y, et al (2017). Abdominal obesity and colorectal cancer risk: systematic review and meta-analysis of prospective studies. Biosci Rep, 37, BSR20170945.

dos Santos Silva I (1999). Cancer epidemiology: principles and methods. Lion, France: IARC, p 441.

Dvoyrin VV, Aksel EM (1987). Component analysis of the dynamics of malignant neoplasms: guidelines. Moscow, 130 p. (Russian).

Dyson JK, Rutter MD (2012). Colorectal cancer in inflammatory bowel disease: what is the real magnitude of the risk?. World $J$ Gastroenterol, 18, 3839-48.

Eaden JA, Abrams KR, Mayberry JF (2001). The risk of colorectal cancer in ulcerative colitis: a meta-analysis. Gut, 48, 526-35.

Eskola M, Elliott CT, Hajšlová J, Steiner D, Krska R (2020). Towards a dietary-exposome assessment of chemicals in food: An update on the chronic health risks for the European consumer. Crit Rev Food Sci Nutr, 60, 1890-1911.

Ferlay J, Ervik M, Lam F, et al (2020A). Global Cancer Observatory: Cancer Today. Lyon, France: International Agency for Research on Cancer [cited 2021 Feb 25]. Available from: https://gco.iarc.fr/today.

Ferlay J, Laversanne M, Ervik M, et al (2020B). Global Cancer Observatory: Cancer Tomorrow. Lyon, France: International Agency for Research on Cancer [cited 2021 Feb 25]. Available from: https://gco.iarc.fr/tomorrow.

Fliss-Isakov N, Zelber-Sagi S, Webb M, Halpern Z, Kariv R (2018). Smoking habits are strongly associated with colorectal polyps in a population-based case-control study. J Clin Gastroenterol, 52, 805-11.

Glanz S (1998). Biomedical statistics. Moscow: Practice, p. 459 (Russian).

Gu MJ, Huang QC, Bao CZ, et al (2018). Attributable causes of colorectal cancer in China. BMC Cancer, 18, 38.

Heisser T, Cardoso R, Guo F, et al (2021). Strongly divergent impact of adherence patterns on efficacy of colorectal cancer screening: The Need to Refine Adherence Statistics. Clin Transl Gastroenterol, 12, e00399.

Huxley RR, Ansary-Moghaddam A, Clifton P, et al (2009). The impact of dietary and lifestyle risk factors on risk of colorectal cancer: a quantitative overview of the epidemiological evidence. Int J Cancer, 125, 171-80.

Igissinov N, Akshulakov S, Kerimbayev T, et al (2015). Malignant tumors of the central nervous system in Kazakhstan: component analysis of incidence dynamics. Asian Pac J Cancer Prev, 16, 2289-93.

Igissinov N, Kozhakhmetov S, Zhantubetova M, et al (2019). Thyroid Cancer in Kazakhstan: Component Analysis of Incidence Dynamics. Asian Pac J Cancer Prev, 20, 2875 2880.

Igissinov S, Igissinov N, Moore MA, et al (2013). Component analysis of esophageal cancer incidence in Kazakhstan. Asian Pac J Cancer Prev, 14, 1945-9.

Igissinov S, Igissinov N, Seytkazina G (2012). Component analysis of the incidence of malignant tumors of the population of Kazakhstan from 1999 to 2010 . Oncol Radiol Kazakhstan, 1, 3-8 (in Russian).

Johnson CM, Wei C, Ensor JE, et al (2013). Meta-analyses of colorectal cancer risk factors. Cancer Causes Control, 24, 1207-22.

Kearney J (2010). Food consumption trends and drivers. Philos Trans $R$ Soc Lond B Biol Sc, 365, 2793-2807.

Keum N, Giovannucci E (2019). Global burden of colorectal cancer: emerging trends, risk factors and prevention strategies. Nat Rev Gastroenterol Hepatol, 16, 713-32.

Kuanyshkaliyeva A, Igissinov N, Turgambayeva A (2016). Estimation of the change of ovarian cancer incidence in Kazakhstan: Component Analysis of Its Dynamics with the Consideration of Ethnic Features. Iran J Public Health, 45, 1012-9.

Ladabaum U, Dominitz JA, Kahi C, Schoen RE (2020). Strategies for colorectal cancer screening. Gastroenterology, 158, 418-32.

Lauby-Secretan B, Vilahur N, Bianchini F, Guha N, Straif K (2018). International Agency for Research on Cancer Handbook Working Group. The IARC Perspective on Colorectal Cancer Screening. N Engl J Med, 378, 1734-40.

Liu X, Steele JC, Meng XZ (2017). Usage, residue, and human health risk of antibiotics in Chinese aquaculture: A review. Environ Pollut, 223, 161-9.

Lucas C, Barnich N, Nguyen HTT (2017). Microbiota, Inflammation and Colorectal Cancer. Int J Mol Sci, 18, 1310.

Mármol I, Sánchez-de-Diego C, Pradilla Dieste A, Cerrada E, Rodriguez Yoldi MJ (2017). Colorectal Carcinoma: A General Overview and Future Perspectives in Colorectal Cancer. Int J Mol Sci, 18, 197.

Mattiuzzi C, Sanchis-Gomar F, Lippi G (2019). Concise update on colorectal cancer epidemiology. Ann Transl Med, 7, 609.

Merabishvili VM (2015). Oncological statistics (traditional methods, new information technologies): A guide for physicians. Second edition, supplemented. Part I, 223 p.

Merkov AM, Polyakov LY (1974). Health Statistics. Leningrad: Medicine, 384 p. (Russian).

Muckelbauer R, Gortmaker SL, Libuda L, et al (2016). Changes in water and sugar-containing beverage consumption and body weight outcomes in children. Br J Nutr, 115, 2057-66.

Murphy N, Ward HA, Jenab M, et al (2019). Heterogeneity of colorectal cancer risk factors by anatomical subsite in 10 European Countries: A Multinational Cohort Study. Clin Gastroenterol Hepatol, 17, 1323-31.e6.

Nadeem MS, Kumar V, Al-Abbasi FA, Kamal MA, Anwar F (2020). Risk of colorectal cancer in inflammatory bowel diseases. Semin Cancer Biol, 64:51-60.

National Cancer Institute (2013). Recommendations on the use of the World Standard (WHO 2000-2025) [cited 2020 Apr 15]. Available from: http://seer.cancer.gov/stdpopulations/ world.who.html.

Oliveira NA, Gonçalves BL, Lee SH, Oliveira CAF, Corassin $\mathrm{CH}$ (2020). Use of Antibiotics in Animal Production and its Impact on Human Health. J Food Chem Nanotechnol, 6, 40-7.

Orlien V, Bolumar T (2019). Biochemical and Nutritional Changes during Food Processing and Storage. Foods, 8, 494.

Rawla P, Sunkara T, Barsouk A (2019). Epidemiology of colorectal cancer: incidence, mortality, survival, and risk factors. Prz Gastroenterol, 14, 89-103.

Rex DK, Boland CR, Dominitz JA, et al (2017). Colorectal Cancer Screening: Recommendations for Physicians 
and Patients From the U.S. Multi-Society Task Force on Colorectal Cancer. Gastroenterology, 153, 307-23.

Siegel RL, Fedewa SA, Anderson et al (2017). Colorectal Cancer Incidence Patterns in the United States, 1974-2013. J Natl Cancer Inst, 109, djw322.

Tango T (2010). Statistical Methods for Disease Clustering, Statistics for Biology and Health Series, New York: Springer, $247 \mathrm{p}$.

Valle L (2017). Recent discoveries in the genetics of familial colorectal cancer and polyposis. Clin Gastroenterol Hepatol, 15, 809-19.

White A, Ironmonger L, Steele R, et al (2018). A review of sexrelated differences in colorectal cancer incidence, screening uptake, routes to diagnosis, cancer stage and survival in the UK. BMC Cancer, 18, 906.

Winawer SJ, St John DJ, Bond JH, et al (1995). Prevention of colorectal cancer: guidelines based on new data. WHO Collaborating Center for the Prevention of Colorectal Cancer. Bulletin of the World Health Organization, 73, 7.

Yang J, Yu J (2018). The association of diet, gut microbiota and colorectal cancer: what we eat may imply what we get. Protein Cell, 9, 474-87.

Zholmurzaeva R, Ospanova D, Pak L, et al (2021). Screening results of colorectal cancer in the Almaty region of the Republic of Kazakhstan - features and modifying factors of efficiency. Sci Healthcare, 23, 56-64.

Zhylkaidarova A, Kaidarova D, Batyrbekov K, Shatkovskaya O, Begimbetova D (2021). Trends of Colorectal Cancer Prevalence in Kazakhstan Related to Screening. Clin Endosc, 54, 32-7.

\section{(c) (i) (9)}

This work is licensed under a Creative Commons AttributionNon Commercial 4.0 International License. 